\title{
Individual Variation in the Motivational and Neurobiological Effects of an Opioid Cue
}

\author{
Lindsay M Yager', Kyle K Pitchers', Shelly B Flagel' ${ }^{1,2,3}$ and Terry E Robinson*,I \\ 'Department of Psychology (Biopsychology Program), University of Michigan, Ann Arbor, MI, USA; ${ }^{2}$ Department of Psychiatry, University of \\ Michigan, Ann Arbor, MI, USA; ${ }^{3}$ Molecular and Behavioral Neuroscience Institute, University of Michigan, Ann Arbor, MI, USA
}

\begin{abstract}
A discrete cue associated with intravenous injections of cocaine acquires greater control over motivated behavior in some rats ('signtrackers', STs) than others ('goal-trackers', GTs). It is not known, however, if such variation generalizes to cues associated with other drugs. We asked, therefore, whether a discrete cue (a light) associated with the intravenous administration of an opioid drug (the shortacting mu receptor agonist, remifentanil) acquires incentive motivational properties differently in STs and GTs, as indicated by tests of Pavlovian conditioned approach and conditioned reinforcement. Consistent with studies using cocaine, STs approached a classically conditioned opioid cue more readily than GTs, and in a test of conditioned reinforcement worked more avidly to get it. Interestingly, STs and GTs did not differ in the acquisition of a conditioned orienting response. In addition, the performance of conditioned approach behavior, but not conditioned orientation, was attenuated by pretreatment with the dopamine receptor antagonist, flupenthixol, into the core of the nucleus accumbens. Lastly, food and opioid cues engaged similar amygdalo-striatal-thalamic circuitry to a much greater extent in STs than GTs, as indicated by Fos expression. Taken together, these data demonstrate that, similar to food and cocaine cues: (1) a discrete opioid cue attains greater incentive motivational value in STs than GTs; (2) the attribution of incentive motivational properties to an opioid cue is dopamine dependent; and (3) an opioid cue engages the so-called 'motive circuit' only if it is imbued with incentive salience.

Neuropsychopharmacology (2015) 40, 1269-1277; doi:I0.1038/npp.20।4.3।4; published online 17 December 20I4
\end{abstract}

\section{INTRODUCTION}

Cues associated with natural or drug rewards can acquire such powerful control over motivated behavior that they are sometimes difficult to resist. There is, however, considerable individual variation in the ability of reward cues to motivate behavior (Mahler and de Wit, 2010; Meyer et al, 2012; Robinson and Flagel, 2009). Preclinical studies suggest this variation is due, at least in part, to intrinsic individual variation in the extent to which reward cues are attributed with incentive salience (Meyer et al, 2012; Robinson and Flagel, 2009; Yager and Robinson, 2010). For example, if a spatially discrete stimulus (a lever; the conditioned stimulus, CS) is repeatedly paired with delivery of a food reward (the unconditioned stimulus, US), in some rats ('sign-trackers', STs; Hearst and Jenkins, 1974), the CS itself becomes attractive, eliciting approach and engagement with it, and desired, in that STs will work to obtain it. In other rats ('goal-trackers', GTs; Boakes, 1977) the CS itself is less attractive-its presentation instead elicits approach to the location where food will be delivered-and GTs do not

*Correspondence: Dr TE Robinson, Department of Psychology (Biopsychology Program), University of Michigan, 530 Church Street, East Hall, Ann Arbor, Ml 48I09, USA, Tel: + I 734763 436I, Fax: +I 734763 7480, E-mail: ter@umich.edu

Received 2 October 2014; revised 13 November 2014; accepted 23 November 20।4; accepted article preview online 26 November 2014 work as avidly to gain access to it. Thus, a CS acquires the properties of an incentive stimulus - the ability to attract and to act as a conditioned reinforcer-to a greater extent in some rats than others (for reviews, see Robinson et al, 2014; Saunders and Robinson, 2013a).

Importantly, the propensity to approach a food cue predicts the extent to which a discrete drug cue acquires motivational properties. For example, relative to GTs, a cocaine cue is more attractive to STs, eliciting greater approach behavior (Flagel et al, 2010; Yager and Robinson, 2013) and more desired, in that STs will work more avidly just for presentation of a cocaine cue (Saunders and Robinson, 2010; Yager and Robinson, 2013). Finally, a cocaine cue spurs greater drug-seeking behavior in STs than GTs (Saunders et al, 2013b). However, all previous studies comparing the ability of a drug cue to motivate behavior in STs and GTs have used cocaine. Therefore, it is not known if such variation generalizes to cues associated with drugs from other classes.

To begin to address this question, we asked whether the propensity to attribute incentive salience to a food cue predicts the extent to which a discrete cue associated with administration of an opioid drug (remifentanil) acquires incentive motivational properties. Remifentanil was chosen for study because not only is it a potent mu receptor agonist, but it also has a very short duration of action, which is advantageous for conditioning studies (Haidar 
et al, 1997). Second, to explore the neurobiology underlying individual variation in the attribution of incentive salience to an opioid cue we asked (a) whether dopamine transmission within the nucleus accumbens core is necessary for expression of conditioned approach to an opioid cue and (b) whether an opioid cue is equally effective in inducing Fos protein expression in brain regions that comprise the 'motive circuit' in STs vs GTs.

\section{MATERIALS AND METHODS}

\section{Pavlovian Training Using Food as the US}

Adult male Sprague-Dawley rats from Harlan (Haslett, MI) and Charles River (Portage, MI) (Fitzpatrick et al, 2013) were acclimated to the colony room for 1 week before Pavlovian training using procedures similar to those described previously (Flagel et al, 2007; Meyer et al, 2012). Briefly, rats underwent five (Experiments 1-3) or seven (Experiment 4) daily sessions of Pavlovian conditioning, during which a lever (lever-CS) was inserted into the chamber 25 times for $8 \mathrm{~s}$, and immediately upon retraction a single 45-mg banana-flavored pellet (the US) was delivered into the food cup. Following completion of training, animals were classed into three groups: (1) those that preferentially interacted with the lever-CS (STs), (2) those that preferentially interacted with the food cup during the lever-CS presentation (GTs), and (3) those that had no strong preference for either the lever-CS or food cup. See Supplementary Methods.

\section{Experiment 1: Individual Variation in Pavlovian} Conditioned Approach using Remifentanil as the US

Following Pavlovian training using food as the US, STs and GTs were outfitted with an intravenous jugular catheter. Behavioral testing was conducted in chambers identical to those used to screen animals for ST and GT, except the food cup and lever were removed from the chamber and two stimulus lights were placed on the left and right sides of the wall opposite the house light, $13.5 \mathrm{~cm}$ above the floor. Before training, rats were assigned to either Paired (CS and US presented together) or unpaired (UP) groups (US explicitly not paired with presentation of the CS). Each session consisted of 22 trials occurring on a variable time (VT) schedule with a mean of $360 \mathrm{~s}$ (300-420 s). For rats in the Paired groups, each trial consisted of illumination of the stimulus light (light-CS) for $10 \mathrm{~s}$, which coincided with an intravenous infusion of 1.6 or $3.2 \mu \mathrm{g} / \mathrm{kg}$ remifentanil hydrochloride (weight of the salt, dissolved in $0.9 \%$ saline in $50 \mu \mathrm{l})$. Rats in the UP group received noncontingent infusions of $3.2 \mu \mathrm{g} / \mathrm{kg}$ remifentanil that were explicitly not paired with illumination of the light-CS (remifentanil was delivered on a VT schedule with a mean of $150 \mathrm{~s}$ after the CS was extinguished). We only tested rats in the UP group with $3.2 \mu \mathrm{g} / \mathrm{kg}$ of remifentanil as this dose produced the most approach in the paired rats.

Video analysis. All Pavlovian conditioning sessions using remifentanil as the US were video-recorded. Video was scored offline by an observer blind to treatment condition for two different conditioned responses (CRs), as described previously (Yager and Robinson, 2013). (1) Conditioned Orientation: an orienting response was scored if the rat made a head and/or body movement in the direction of the CS during the CS period, regardless of whether the rat approached the CS. (2) Conditioned Approach: an approach response was scored if the rat moved towards the CS during the CS period, bringing its nose to within $1 \mathrm{~cm}$ of the light, which required it to rear (Supplementary Methods).

\section{Experiment 2: Individual Variation in the Conditioned Reinforcing Properties of a Pavlovian Conditioned Remifentanil Cue}

One week following the last Pavlovian training session with remifentanil as the US, rats from Experiment 1 underwent a single 40-min test for conditioned reinforcement, in which they had the opportunity to nose poke for presentation of the remifentanil cue (Supplementary Methods).

\section{Experiment 3: The Role of Nucleus Accumbens Core Dopamine in the Expression of Pavlovian Conditioned Approach to a Remifentanil Cue}

An independent cohort of rats was trained on the Pavlovian task using food as the US to identify STs, and only STs were used in this experiment. Rats were then prepared with catheters and guide cannulas placed $2 \mathrm{~mm}$ above the target site in the nucleus accumbens core. Rats then underwent Pavlovian training with remifentanil as the US for 8 days exactly as in Experiment 1. Before the 9th training session, rats were given a vehicle microinjection. Subsequently, rats received microinjections of the dopamine antagonist, flupenthixol $(5,10$, and $20 \mu \mathrm{g})$, in a counterbalanced order, $35 \mathrm{~min}$ before being moved to the testing chambers for the start of the session (Supplementary Methods).

\section{Experiment 4: Individual Variation in Fos Expression Elicited by Pavlovian Conditioned Food and Remifentanil Cues}

Ten days following Pavlovian training using either food or remifentanil as the US, as described above and in the Supplementary Methods, rats were re-exposed to either the food (lever-CS) or remifentanil (light-CS) cue, under extinction conditions, for $4 \mathrm{~s}$ a total of 10 times (once per minute). After the last CS presentation, rats were returned to their home cages, and then 60 min later their brains were obtained and processed for Fos immunohistochemistry (Supplementary Methods).

\section{RESULTS}

STs and GTs both Orient to a Remifentanil Cue, but only STs Avidly Approach it

As reported previously (Flagel et al, 2007; Meyer et al, 2012), two distinct phenotypes emerged as a result of Pavlovian training using food as the US (Supplementary Figure S1; Supplementary Results). STs and GTs were then used to test the attractiveness of a remifentanil cue. Figures $1 \mathrm{a}$ and $\mathrm{c}$ show that with both doses of remifentanil, paired STs and GTs acquired a conditioned orienting response, as 
Orientation

Approach

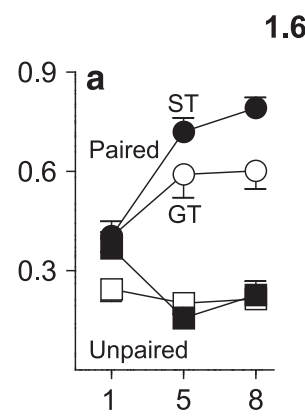

$1.6 \mu \mathrm{g} / \mathrm{kg}$

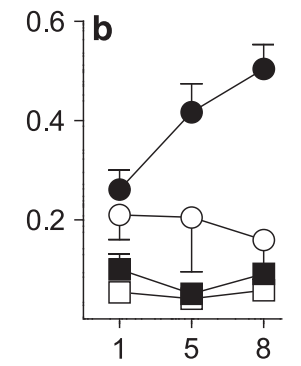

$3.2 \mu \mathrm{g} / \mathrm{kg}$
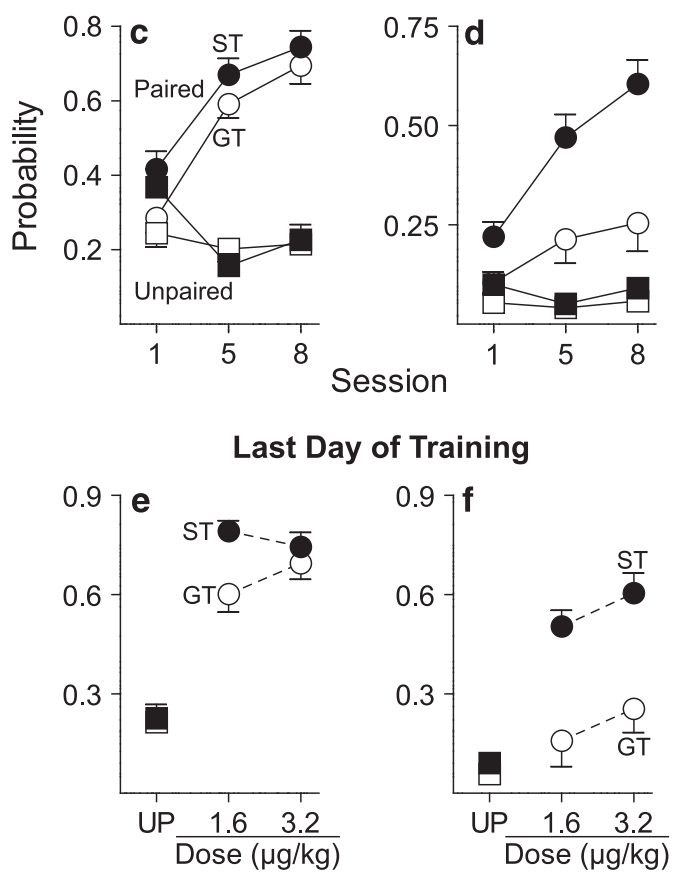

Figure I CS-directed orientation and approach to a cue associated with a noncontingent intravenous injection of remifentanil. All Unpaired rats were trained with $3.2 \mu \mathrm{g} / \mathrm{kg}$ remifentanil (STs $n=10$, GTs $n=11$ ). Data represent means \pm SEM. Probability of orientation (a) and approach (b) to the remifentanil cue in rats that received $1.6 \mu \mathrm{g} / \mathrm{kg}$ remifentanil as the US (Paired STs $n=1 \mathrm{I}, \mathrm{GTs} n=8$ ). Probability of orientation (c) and approach (d) to the remifentanil cue in rats that received $3.2 \mu \mathrm{g} / \mathrm{kg}$ remifentanil as the US (Paired STs $n=12$, GTs $n=10$ ). Dose-response functions for the probability of conditioned orientation (e) and approach ( $f$ ) on the final day of training where each data point represents an independent group of rats. CS, conditioned stimulus; GT, goal-trackers; ST, sign-trackers; UP, unpaired.

indicated by a significant increase in the probability of orienting behavior across sessions $(1.6 \mu \mathrm{g} / \mathrm{kg}: \quad F(2$, $39.25)=23.59, \quad p<0.001 ; \quad 3.2 \mu \mathrm{g} / \mathrm{kg}: \quad F(2, \quad 18)=99.62$, $p<0.001$ ), and they did so at a similar rate, as indicated by nonsignificant group effects and nonsignificant group by session interactions. However, Figures $1 \mathrm{~b}$ and $\mathrm{d}$ show that with both doses of remifentanil paired STs more readily approached the remifentanil cue than did GTs (effect of group, $1.6 \mu \mathrm{g} / \mathrm{kg}: F(1,45.04)=15.17, p<0.001 ; 3.2 \mu \mathrm{g} / \mathrm{kg}$ : $F(1,45.59)=20.18, p<0.001$; group $\times$ session interaction, $1.6 \mu \mathrm{g} / \mathrm{kg}: \quad F(2, \quad 41.38)=3.84, \quad p=0.03 ; \quad 3.2 \mu \mathrm{g} / \mathrm{kg}: \quad$ n.s. $)$. Importantly, neither STs nor GTs in the unpaired group acquired an orienting or approach CR. Figures $1 e$ and $f$ summarize the dose-response functions for the probability of conditioned orientation and approach on the final day of training (Supplementary Results).

\section{A Remifentanil Cue is a more Effective Conditioned Reinforcer in STs than GTs}

Figure 2 shows the mean difference in responses into the Active minus the Inactive port during the conditioned reinforcement test. A one-way ANOVA resulted in a significant main effect of group for both doses $(1.6 \mu \mathrm{g} / \mathrm{kg}$ : $F(2, \quad 37)=20.09, \quad p<0.001 ; \quad 3.2 \mu \mathrm{g} / \mathrm{kg}: \quad F(2, \quad 40)=8.11$, $p=0.001)$. Follow-up tests indicated that, with both training doses, STs made more responses than either GTs or the UP group $(p$ 's $<0.01)$, whereas GTs and the UP group only differed from one another when $1.6 \mu \mathrm{g} / \mathrm{kg}$ remifentanil was used during conditioning $(p=0.02)$.

\section{Dopamine Receptor Blockade in the Nucleus Accumbens Core Suppresses Conditioned Approach to a Remifentanil Cue, but not Conditioned Orientation}

Pavlovian training with food as the US was very similar to Experiment 1; therefore, these data are not shown. It is important to point out that this experiment only utilized rats identified as STs. As in Experiment 1, STs acquired orienting and approach CRs (main effect of session, orientation: $F(2,18.03)=54.29, p<0.001$; approach: $F(2$, $17.06)=26.99, p<0.001$; Figure $3 \mathrm{a}$ ). Upon review of video from the test sessions, we found that the $20-\mu \mathrm{g}$ dose of flupenthixol produced nonspecific motor effects (Supplementary Figure S2; Supplementary Results). Thus, data using this dose were not included in any further analyses. Figure $3 \mathrm{~b}$ shows that flupenthixol dose-dependently decreased approach to the remifentanil cue $(F(2$, $15.22)=47.409, p<0.001)$ without affecting conditioned orientation $(F(2,14)=3.565, p=0.17)$, and did so on the very first trial (that is, in the absence of any new learning; Figure 3c; $F(2,16.973)=4.98, p=0.02)$. See Supplementary Results for details and Supplementary Figure S3 for locations of microinjection tips.

\section{Both Food and Remifentanil Cues Elicit much Greater Fos Expression throughout the 'Motive Circuit' in STs than GTs}

Pavlovian training with food and remifentanil as the US were the same as in Experiment 1 and produced similar effects (Supplementary Figures S4 and S5; Supplementary Results). Figure 4 shows the mean $( \pm$ SEM) number of Fospositive cells in STs and GTs, exposed to either the food or the remifentanil cue, expressed as a percent of Fos-positive cells in the relevant UP control group (food or remifentanil used as the US). The actual cell counts for each group are shown in Supplementary Table S1, and one-way ANOVAs were conducted on the number of Fos cells as a function of group, and not the percent data. The graphs depict the data as a percent of the respective UP group to decrease the number of bars used in each graph, which facilitates visually making group comparisons. 


\section{Fos Immunoreactivity}

In the nucleus accumbens core and shell, dorsomedial and dorsolateral striatum, basolateral amygdala, lateral habenula, and paraventricular and intermediodorsal nuclei of the thalamus, presentation of both the food and the remifentanil cue elicited greater Fos expression in STs than in GTs or the respective UP group, which did not differ from one another (Figure 4; all p's $<0.05$; Supplementary Results). There were no significant group differences in Fos expression elicited by either the food or the remifentanil cue in any region of the prefrontal cortex we analyzed or in the medial habenula. In the central nucleus of the amygdala,

\section{Conditioned Reinforcement}

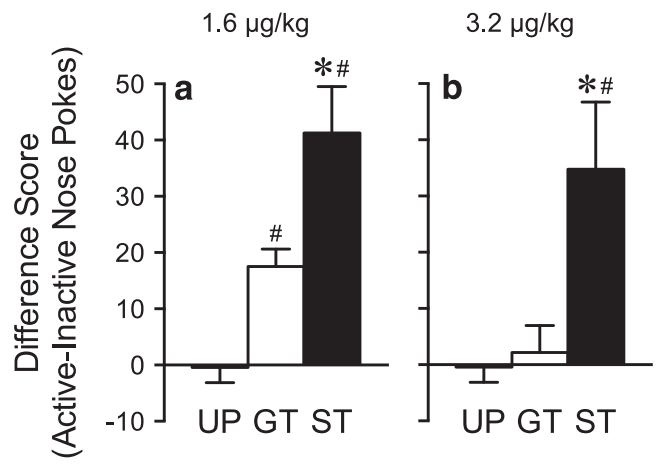

Figure 2 Performance during the conditioned reinforcement test. During this 40-min test, a nose poke into one port (Active) resulted in 2-s presentation of the cue either previously paired or unpaired with noncontingent remifentanil delivery. Nose pokes into the other port (Inactive) had no consequence. All UP rats were trained with $3.2 \mu \mathrm{g} / \mathrm{kg}$ remifentanil $(n=21)$. Data represent the means \pm SEM difference in nose pokes into the Active minus Inactive port for rats that were trained with (a) $1.6 \mu \mathrm{g} / \mathrm{kg}$ remifentanil (Paired STs $n=1 \mathrm{I}$, GTs $n=8$ ) or $(\mathrm{b}) 3.2 \mu \mathrm{g} / \mathrm{kg}$ remifentanil (Paired STs $n=12, G T s n=10$ ). *, indicates a significant group difference between STs and GTs. \#, indicates a significant difference from UP. p<0.05.GT, goal-trackers; ST, sign-trackers; UP, unpaired. presentation of the food cue elicited greater Fos expression in STs than the UP food group, whereas there were no significant group differences in Fos expression after presentation of the remifentanil cue (food: $F(2$, $14)=6.055, \quad p=0.013$; remifentanil: $F(2,15)=0.565$, $p=0.58)$. However, in the central medial nucleus of the thalamus, there were significant group differences in Fos expression elicited by the remifentanil cue, but not by the food cue (food: $F(2,14)=2.851, p=0.091$; remifentanil: $F(2$, $15)=5.971, p=0.012$ ). Figure 5 provides a visual summary of these results.

\section{DISCUSSION}

It is clear that cues associated with opioid drugs can be attributed with incentive salience. Opioid cues are attractive (Madsen and Ahmed, 2014; Peters and De Vries, 2013) and act as conditioned reinforcers (Bertz et al, 2014; Bertz and Woods, 2013). Of course, studies on opioid cue-induced reinstatement of drug-seeking behavior are consistent with this notion (Davis and Smith, 1976; Shalev et al, 2002). Here we were specifically interested in whether the propensity to attribute incentive salience to a food cue predicts variation in the extent to which an opioid (remifentanil) cue acquires motivational properties, as previously shown for a cocaine cue (Flagel et al, 2010; Saunders and Robinson, 2010; Saunders et al, 2013b; Yager and Robinson, 2013). It did.

\section{Individual Variation in the Motivational Properties of an Opioid Cue}

First, STs more readily approached the remifentanil cue than did GTs. Second, the remifentanil cue was a more effective conditioned reinforcer in STs than GTs. Interestingly, there was no difference between STs and GTs in the acquisition of a conditioned orienting response to the remifentanil cue. This is important because with drug as the
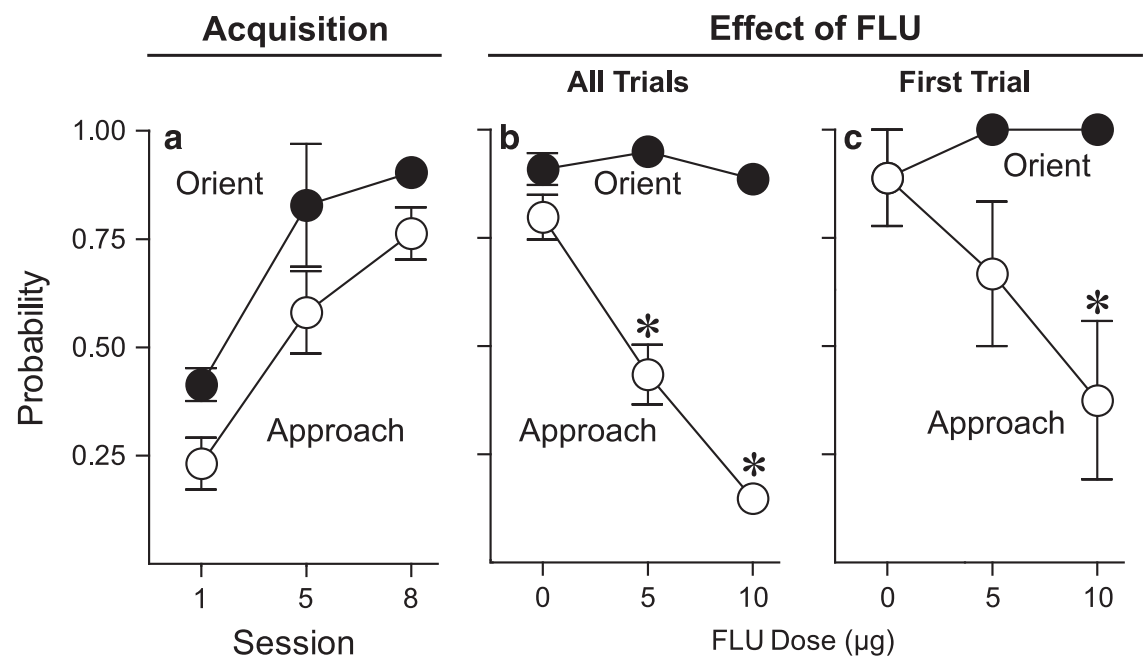

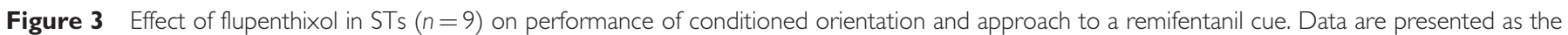

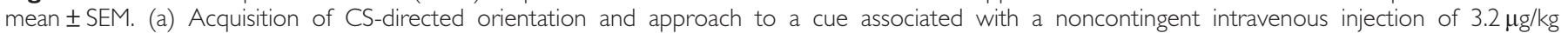

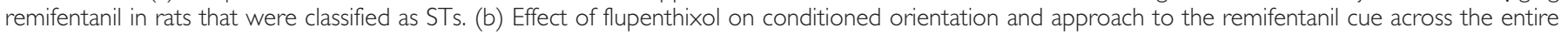

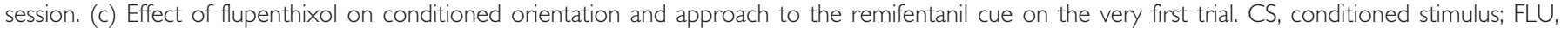
flupenthixol; GT, goal-trackers; ST, sign-trackers; UP, unpaired. *, indicates significant difference relative to vehicle. $p<0.05$. 


\section{Neocortex}
Orbitofrontal
Anterior
Prelimbic
Infralimbic
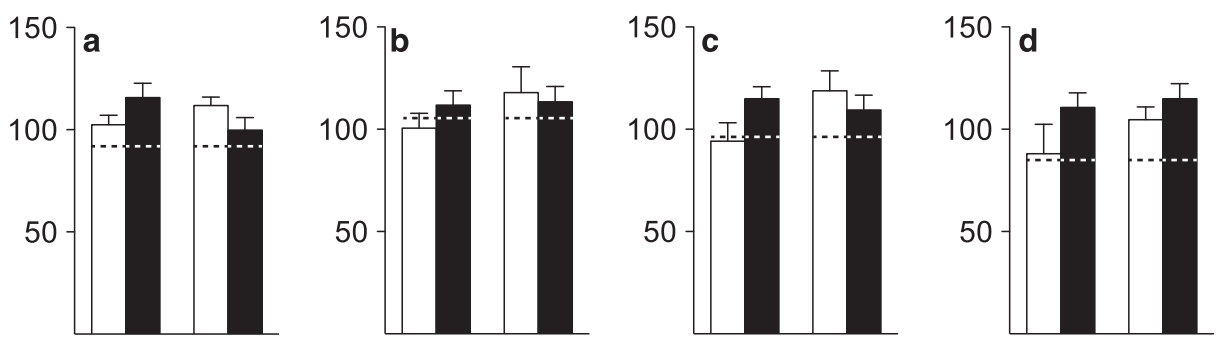

\section{Striatum}

NAc Core NAc Shell

DM Striatum

DL Striatum
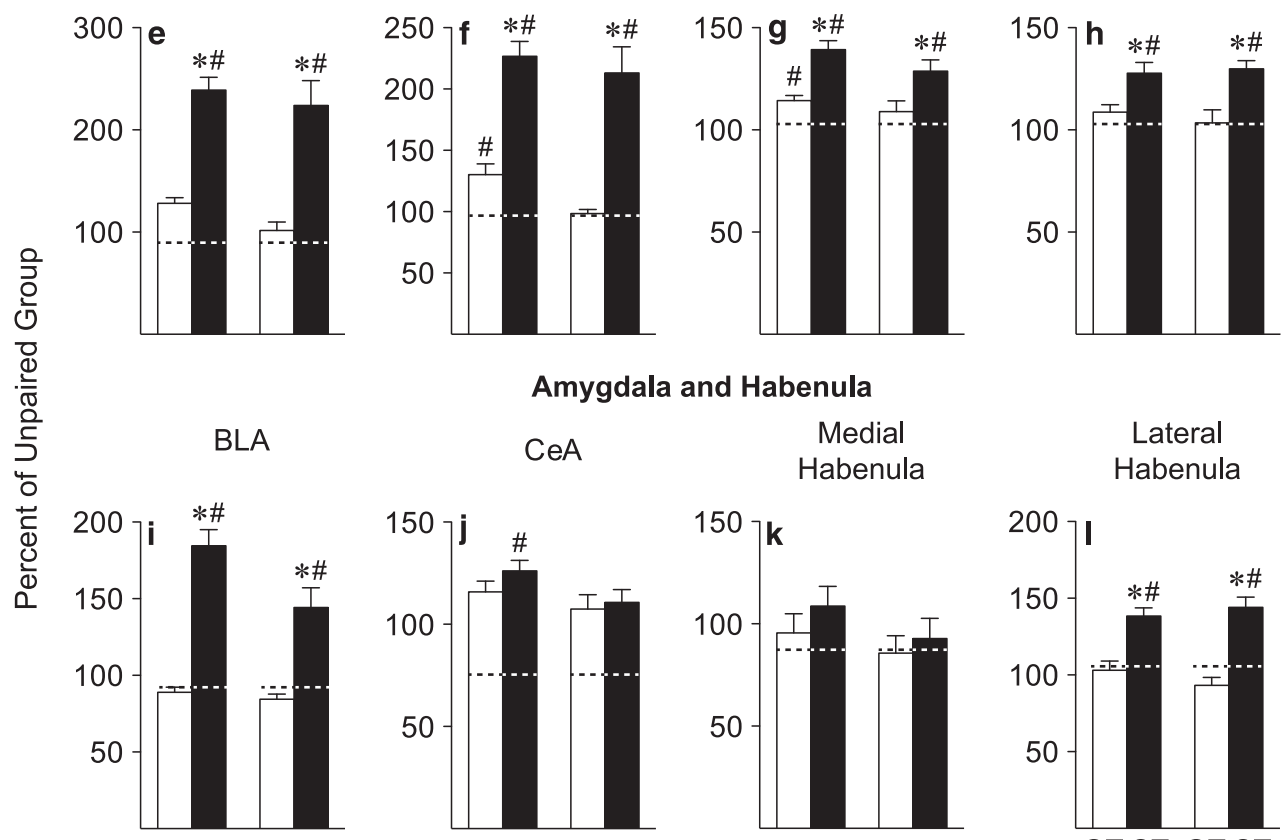

Amygdala and Habenula

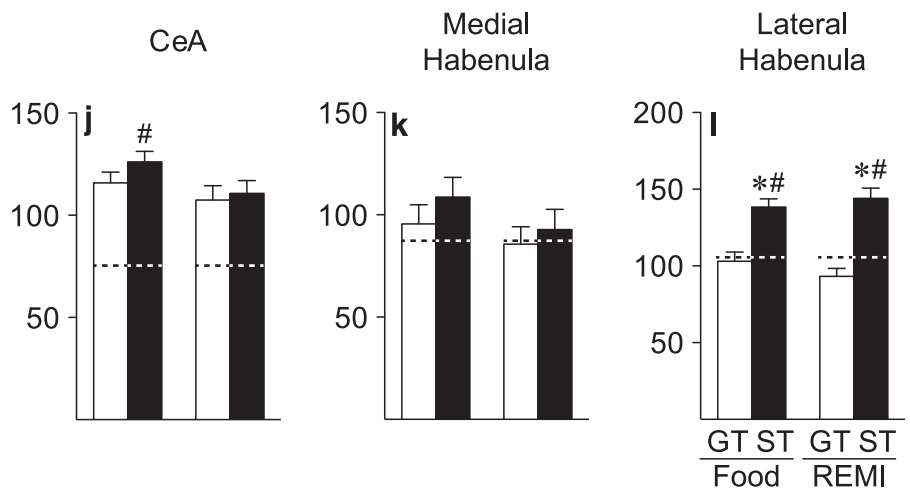

Thalamus

IMD

CeM
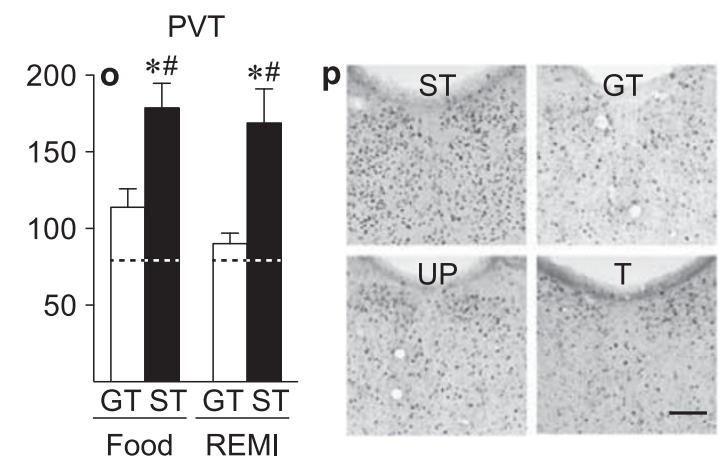

Figure 4 Mean \pm SEM percent of Fos cells relative to the respective unpaired (UP) groups (UP food cue $n=6$, UP remifentanil cue $n=6)$ in the (a) orbitofrontal cortex, (b) anterior cingulate cortex, (c) prelimbic cortex, (d) infralimbic cortex, (e) NAc core, (f) NAc shell, (g) DM striatum, (h) DL striatum, (i) BLA, (j) CeA, (k) medial habenula, (I) lateral habenula, (m) IMD, (n) CeM, and (o) PVT of rats presented with either the food cue (STs $n=6$, GTs $n=5$ ) or the REMI cue (STs $n=6, G T s n=6$ ) on the test day. Dashed lines indicate the percent of Fos cells in transport control rats relative to unpaired rats. ( $P$ ) Representative images of PVT sections immunostained for Fos in each experimental group. BLA, basolateral amygdala; CeA, central nucleus of the amygdala; CeM, central medial nucleus of the thalamus; DM, dorsomedial; DL, dorsolateral; IMD, intermedidorsal nucleus of the thalamus; NAc, nucleus accumbens; PVT, paraventricular nucleus of the thalamus; REMI, remifentanil; T, transport control; UP, unpaired. *, indicates a significant difference from GTs. ${ }^{\#}$, indicates a significant difference from UP. $p<0.05$. Scale bar, $100 \mu \mathrm{m}$. 


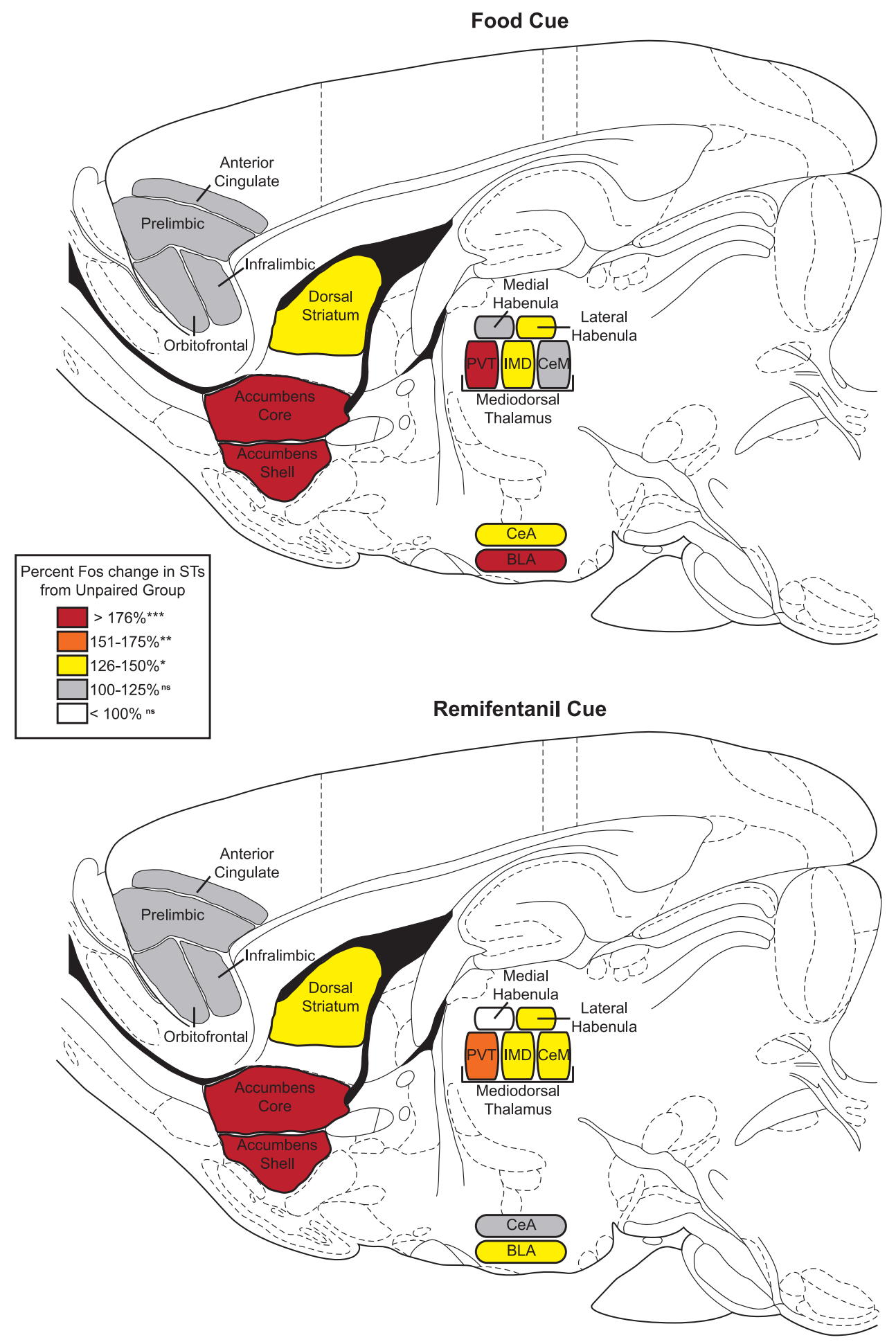

Figure 5 Summary of Fos changes after presentation of either the food or remifentanil cue. Colors represent the percent change in Fos activation in STs compared with the Unpaired control groups. BLA, basolateral amygdala; CeA, central nucleus of the amygdala; CeM, central medial nucleus of the thalamus; IMD, intermedidorsal nucleus of the thalamus; PVT, paraventricular nucleus of the thalamus. ns, nonsignificant, $p>0.05$; $* p<0.05$; $* * * 0.0$; $* * * * * 0.00$ I.

US there is no 'goal' to approach. It is also consistent with previous findings for both food and cocaine cues (Yager and Robinson, 2013). We conclude that GTs did not approach the remifentanil cue because it was not attributed with sufficient incentive salience to attract animals into close proximity with it, even though they did learn the CS-
US association (they acquire a conditioned orienting response). Thus, variation in the propensity to attribute incentive salience to reward cues is seen using food cues and cues associated with drugs from at least two different classes, suggesting that this represents a fundamental trait (for example, Meyer et al, 2012). 


\section{Dopamine and Pavlovian Conditioned Approach}

It is well established that the primary rewarding effects of psychomotor stimulant drugs are mediated by dopamine neurotransmission within the nucleus accumbens (NAc; Di Chiara and Imperato, 1988; Lyness et al, 1979; Roberts et al, 1980; Wise and Bozarth, 1987), but this might not be the case for opioids (for review see Badiani et al (2011). For example, systemic blockade of dopamine receptors and either selective lesions of dopamine terminals or blockade of dopamine D1 receptors within the NAc decreases cocaine self-administration but has little to no effect on heroin selfadministration (Ettenberg et al, 1982; Gerrits et al, 1994; Maldonado et al, 1993; Pettit et al, 1984).

Although the primary reinforcing effects of opioids may not be dopamine-dependent, dopamine does appear to be required for cues associated with opioids to acquire secondary (conditioned) reinforcing effects. For example, systemic injection of dopamine receptor antagonists or injection of a dopamine D1 receptor antagonist into the NAc core attenuated the reinstatement of heroin seeking by heroin-associated cues (Bossert et al, 2007; Lai et al, 2013), indicating that the ability of an opioid cue to serve as a conditioned reinforcer requires dopamine. Here we show that dopamine in the NAc core is also required for a remifentanil cue to elicit a sign-tracking $\mathrm{CR}$, which is thought to reflect the extent to which the cue is attributed with incentive salience (Flagel et al, 2011b; Saunders and Robinson, 2012). Importantly, although flupenthixol dosedependently reduced conditioned approach behavior, it had no effect on conditioned orienting, as reported previously when food was used as the US (Saunders and Robinson, 2012). This suggests that the decrement in approach behavior was not because dopamine blockade degraded the CS-US association, but specifically attenuated the incentive value of the cue, necessary for it to remain attractive. Consistent with this interpretation, flupenthixol suppressed approach behavior on the very first trial, indicating that the decrement in performance occurred in the absence of new learning. These findings, together with our previous reports (Flagel et al, 2011b; Saunders and Robinson, 2012; Saunders et al, 2013b), indicate that dopamine transmission within the NAc core is necessary for maintaining the motivational properties of multiple classes of reward cues, including opioid cues.

\section{Engagement of 'Motive Circuitry' by Reward Cues}

There is now a wealth of evidence in both humans and nonhuman animals that cues associated with different classes of rewards (for example, food, drugs, and sex) engage overlapping neural systems, including the mesocorticolimbic dopamine system and other cortico-striatal-thalamic loops that comprise a so-called 'motive circuit' (Childress et al, 1999; Frohmader et al, 2010; Kelley et al, 2005; Tang et al, 2012; Tomasi et al, 2014). However, in most studies the predictive and incentive values of cues are confounded, and it is not possible to know which property of a cue is sufficient to engage these neural circuits. It is important, therefore, that Flagel et al (2011a) reported that the predictive value of a food cue is not sufficient to engage motivational circuitry-it must be imbued with incentive salience (that is, it did so in STs but not GTs). Here we asked whether this would also be the case for an opioid cue and whether food and opioid cues engaged similar circuitry.

In almost every region we examined, both the food and remifentanil cues elicited greater Fos expression in STs relative to GTs, or rats that received UP CS-US presentations. Furthermore, there were a number of regions (for example, NAc core, dorsolateral striatum, midline thalamic nuclei, basolateral amygdala, and lateral habenula) where presentation of either the food or remifentanil cue had no effect on Fos expression in GTs (that is, they did not differ from the UP groups) while presentation of either cue produced robust Fos expression in STs. However, one limitation of the study is that Fos was only quantified from a portion of each structure and may not be representative of the entire region. Interestingly, these data parallel some recent human imaging work that has shown individual variation in the ability of both food and drug cues to elicit brain activity throughout the 'motive circuit' (Beaver et al, 2006; Janes et al, 2010; Kilts et al, 2014). It was also interesting that the food and opioid cue engaged essentially the same brain regions in STs. However, there were a few brain areas where we found a dissociation between subregions in the extent to which both the food and the remifentanil cue elicited Fos expression. For example, presentation of the food and remifentanil cue elicited robust Fos expression in STs within the basolateral amygdala (BLA) but not in the central nucleus of the amygdala (CeA). This finding is consistent with a series of studies showing that, whereas lesions of the BLA attenuate ST behavior, lesions of the CeA do not affect acquisition or expression of sign-tracking behavior (Chang et al, 2012a,b). In addition, presentation of the food and remifentanil cue elicited robust Fos expression in the lateral habenula of STs, but not the medial habenula, which is consistent with the ability of an opioid cue to reinstate drug-seeking behavior and increase Fos expression in the lateral habenula (Madsen et al, 2012). Interestingly, Danna et al (2013) recently reported that modulation of lateral habenula outputs strongly influences sign-tracking, but not goal-tracking behavior, perhaps because of its influence on dopamine neurotransmission.

We should point out that the food cup may also have incentive value, as both STs and GTs eventually approach the location of food delivery (DiFeliceantonio and Berridge, 2012; Mahler and Berridge, 2009). However, in Flagel et al (2011a), the food cup was removed from the chamber on test day to specifically isolate the ability of the food cue to elicit c-fos mRNA expression. Thus, they could not assess c-fos mRNA expression when a GT CR was made. It is possible that approach to the food cup might be sufficient to activate some of the same brain regions in GTs as in STs. For this reason, we decided to leave the food cup in the chamber on the test day. Nevertheless, we did not find any region where Fos expression was greater in GTs than in STs. One possible explanation for this is that the 3 days before the cue exposure test day, rats were placed into the chambers (with the food cup present) to minimize the influence of any contextual cues. These habituation sessions may have decreased the amount of goal-tracking observed on the test day (Supplementary Figure S4), which may have resulted in less overall Fos expression in GTs. 


\section{CONCLUSIONS}

The propensity of an individual to attribute incentive salience to a food cue predicted the extent to which an opioid (remifentanil) cue became attractive and desired, consistent with previous studies using cocaine (Robinson et al, 2014). In addition, the ability of a remifentanil cue to motivate approach behavior required dopamine transmission within the NAc core, and a distributed network of brain regions that comprises a so-called 'motive circuit', including the dopamine-rich ventral and dorsal striatum, were engaged by food and opioid cues only if they were attributed with incentive salience. It is important to emphasize that in GTs both the food and remifentanil cues functioned as fully predictive CSs, evoking CRs, but this property was not sufficient to engage this circuitry. This dissociation suggests that these brain regions may be especially important in mediating motivational processes. The dopamine system has been the primary focus of research on incentive motivation and reward, but the diversity of brain regions selectively engaged in STs suggests that a number of other brain regions deserve attention. For example, the paraventricular nucleus of the thalamus (for review see Haight and Flagel (2014), the BLA (Chang et al, 2012a,b), and the lateral habenula (Danna et al, 2013) all appear to exert different effects on sign-tracking than on goal-tracking behavior. It is also of note that the food and opioid cues engaged essentially the same brain reward circuitry, suggesting that similar psychological and neurobiological mechanisms may underlie the attribution of incentive salience to cues associated with very different types of rewards.

\section{FUNDING AND DISCLOSURE}

This research was supported by grants from the National Institute on Drug Abuse to LMY (F31 DA030799) and TER (P01 DA031656). The authors declare no conflicts of interest.

\section{ACKNOWLEDGEMENTS}

We thank Anusari Dewasurendra, Kyle Eaton, and Elizabeth O’Donnell for assistance with behavioral testing.

\section{DISCLAIMER}

The content is solely the responsibility of the authors and does not necessarily represent the official views of the National Institute on Drug Abuse of the National Institutes of Health.

\section{REFERENCES}

Badiani A, Belin D, Epstein D, Calu D, Shaham Y (2011). Opiate versus psychostimulant addiction: the differences do matter. Nat Rev Neurosci 12: 685-700.

Beaver JD, Lawrence AD, van Ditzhuijzen J, Davis MH, Woods A, Calder AJ (2006). Individual differences in reward drive predict neural responses to images of food. J Neurosci 26: 5160-5166.

Bertz JW, Chen J, Woods JH (2014). Effects of pramipexole on the acquisition of responding with opioid-conditioned reinforcement in the rat. Psychopharmacology (Berl) e-pub ahead of print 3 July 2014 doi:10.1007/s00213-014-3659-2.
Bertz JW, Woods JH (2013). Acquisition of responding with a remifentanil-associated conditioned reinforcer in the rat. Psychopharmacology (Berl) 229: 235-243.

Boakes R (1977). Performance on learning to associate a stimulus with positive reinforcement. In: Davis $H$, Hurwits $H$ (eds) Operant-Pavlovian Interactions. Lawrence Erlbaum Associates: Hillsdale, pp 67-97.

Bossert JM, Poles GC, Wihbey KA, Koya E, Shaham Y (2007). Differential effects of blockade of dopamine D1-family receptors in nucleus accumbens core or shell on reinstatement of heroin seeking induced by contextual and discrete cues. J Neurosci 27: 12655-12663.

Chang SE, Wheeler DS, Holland PC (2012a). Effects of lesions of the amygdala central nucleus on autoshaped lever pressing. Brain Res 1450: 49-56.

Chang SE, Wheeler DS, Holland PC (2012b). Roles of nucleus accumbens and basolateral amygdala in autoshaped lever pressing. Neurobiol Learn Mem 97: 441-451.

Childress AR, Mozley PD, McElgin W, Fitzgerald J, Reivich M, O'Brien CP (1999). Limbic activation during cue-induced cocaine craving. Am J Psychiatry 156: 11-18.

Danna CL, Shepard PD, Elmer GI (2013). The habenula governs the attribution of incentive salience to reward predictive cues. Front Hum Neurosci 7: 781.

Davis WM, Smith SG (1976). Role of conditioned reinforcers in the initiation, maintenance and extinction of drug-seeking behavior. Pavlovian J Biol Sci 11: 222-236.

Di Chiara G, Imperato A (1988). Drugs abused by humans preferentially increase synaptic dopamine concentrations in the mesolimbic system of freely moving rats. Proc Natl Acad Sci USA 85: 5274-5278.

DiFeliceantonio AG, Berridge KC (2012). Which cue to 'want'? Opioid stimulation of central amygdala makes goal-trackers show stronger goal-tracking, just as sign-trackers show stronger sign-tracking. Behav Brain Res 230: 399-408.

Ettenberg A, Pettit HO, Bloom FE, Koob GF (1982). Heroin and cocaine intravenous self-administration in rats: mediation by separate neural systems. Psychopharmacology (Berl) 78: 204-209.

Fitzpatrick CJ, Gopalakrishnan S, Cogan ES, Yager LM, Meyer PJ, Lovic $\mathrm{V}$ et al (2013). Variation in the form of Pavlovian conditioned approach behavior among outbred male SpragueDawley rats from different vendors and colonies: sign-tracking vs. goal-tracking. PLoS ONE 8: e75042.

Flagel SB, Cameron CM, Pickup KN, Watson SJ, Akil H, Robinson TE (2011a). A food predictive cue must be attributed with incentive salience for it to induce c-fos mRNA expression in cortico-striatal-thalamic brain regions. Neuroscience 196: 80-96.

Flagel SB, Clark JJ, Robinson TE, Mayo L, Czuj A, Willuhn I et al (2011b). A selective role for dopamine in stimulus-reward learning. Nature 469: 53-57.

Flagel SB, Robinson TE, Clark JJ, Clinton SM, Watson SJ, Seeman P et al (2010). An animal model of genetic vulnerability to behavioral disinhibition and responsiveness to reward-related cues: Implications for addiction. Neuropsychopharmacology 35: 388-400.

Flagel SB, Watson SJ, Robinson TE, Akil H (2007). Individual differences in the propensity to approach signals vs goals promote different adaptations in the dopamine system of rats. Psychopharmacology (Berl) 191: 599-607.

Frohmader KS, Wiskerke J, Wise RA, Lehman MN, Coolen LM (2010). Methamphetamine acts on subpopulations of neurons regulating sexual behavior in male rats. Neuroscience 166: 771-784.

Gerrits MA, Ramsey NF, Wolterink G, van Ree JM (1994). Lack of evidence for an involvement of nucleus accumbens dopamine D1 receptors in the initiation of heroin self-administration in the rat. Psychopharmacology (Berl) 114: 486-494.

Haidar SH, Moreton JE, Liang Z, Hoke JF, Muir KT, Eddington ND (1997). Evaluating a possible pharmacokinetic interaction 
between remifentanil and esmolol in the rat. J Pharm Sci 86: 1278-1282.

Haight JL, Flagel SB (2014). A potential role for the paraventricular nucleus of the thalamus in mediating individual variation in Pavlovian conditioned responses. Front Behav Neurosci 8: 79.

Hearst E, Jenkins HM (1974). Sign Tracking: the StimulusReinforcer Relation and Directed Action. Monograph of the Psychonomic Society: Austin.

Janes AC, Pizzagalli DA, Richardt S, Frederick Bde B, Holmes AJ, Sousa J et al (2010). Neural substrates of attentional bias for smoking-related cues: an FMRI study. Neuropsychopharmacology 35: 2339-2345.

Kelley AE, Schiltz CA, Landry CF (2005). Neural systems recruited by drug- and food-related cues: Studies of gene activation in corticolimbic regions. Physiol Behav 86: 11-14.

Kilts CD, Kennedy A, Elton AL, Tripathi SP, Young J, Cisler JM et al (2014). Individual differences in attentional bias associated with cocaine dependence are related to varying engagement of neural processing networks. Neuropsychopharmacology 39: 1135-1147.

Lai M, Chen W, Zhu H, Zhou X, Liu H, Zhang F et al (2013). Low dose risperidone attenuates cue-induced but not heroin-induced reinstatement of heroin seeking in an animal model of relapse. Int J Neuropsychopharmacol 16: 1569-1575.

Lyness WH, Friedle NM, Moore KE (1979). Destruction of dopaminergic nerve terminals in nucleus accumbens: effect on d-amphetamine self-administration. Pharmacol Biochem Behav 11: 553-556.

Madsen HB, Ahmed SH (2014). Drug versus sweet reward: greater attraction to and preference for sweet versus drug cues. Addict Biol e-pub ahead of print 7 March 2014 doi:10.1111/adb.12134.

Madsen HB, Brown RM, Short JL, Lawrence AJ (2012). Investigation of the neuroanatomical substrates of reward seeking following protracted abstinence in mice. J Physiol 590: 2427-2442.

Mahler SV, Berridge KC (2009). Which cue to 'want?' Central amygdala opioid activation enhances and focuses incentive salience on a prepotent reward cue. J Neurosci 29: 6500-6513.

Mahler SV, de Wit H (2010). Cue-reactors: Individual differences in cue-induced craving after food or smoking abstinence. PLoS ONE 5: e15475.

Maldonado R, Robledo P, Chover AJ, Caine SB, Koob GF (1993). D1 dopamine receptors in the nucleus accumbens modulate cocaine self-administration in the rat. Pharmacol Biochem Behav 45: $239-242$.

Meyer PJ, Lovic V, Saunders BT, Yager LM, Flagel SB, Morrow JD et al (2012). Quantifying individual variation in the propensity to attribute incentive salience to reward cues. PLOS ONE 7: e38987.
Peters J, De Vries TJ (2013). Pavlovian conditioned approach, extinction, and spontaneous recovery to an audiovisual cue paired with an intravenous heroin infusion. Psychopharmacology (Berl) 231: 447-453.

Pettit HO, Ettenberg A, Bloom FE, Koob GF (1984). Destruction of dopamine in the nucleus accumbens selectively attenuates cocaine but not heroin self-administration in rats. Psychopharmacology (Berl) 84: 167-173.

Roberts DC, Koob GF, Klonoff P, Fibiger HC (1980). Extinction and recovery of cocaine self-administration following 6-hydroxydopamine lesions of the nucleus accumbens. Pharmacol Biochem Behav 12: 781-787.

Robinson TE, Flagel SB (2009). Dissociating the predictive and incentive motivational properties of reward-related cues through the study of individual differences. Biol Psychiatry 65: 869-873.

Robinson TE, Yager LM, Cogan ES, Saunders BT (2014). On the motivational properties of reward cues: individual differences. Neuropharmacology 76: 450-459.

Saunders BT, Robinson TE (2010). A cocaine cue acts as an incentive stimulus in some but not others: implications for addiction. Biol Psychiatry 67: 730-736.

Saunders BT, Robinson TE (2012). The role of dopamine in the accumbens core in the expression of Pavlovian-conditioned responses. Eur J Neurosci 36: 2521-2532.

Saunders BT, Robinson TE (2013a). Individual variation in resisting temptation: implications for addiction. Neurosci Biobehav R 37: 1955-1975.

Saunders BT, Yager LM, Robinson TE (2013b). Cue-evoked cocaine 'craving': role of dopamine in the accumbens core. J Neurosci 33: 13989-14000.

Shalev U, Grimm JW, Shaham Y (2002). Neurobiology of relapse to heroin and cocaine seeking: a review. Pharmacol Rev 54: 1-42.

Tang DW, Fellows LK, Small DM, Dagher A (2012). Food and drug cues activate similar brain regions: a meta-analysis of functional MRI studies. Physiol Behav 106: 317-324.

Tomasi D, Wang GJ, Wang R, Caparelli EC, Logan J, Volkow ND (2014). Overlapping patterns of brain activation to food and cocaine cues in cocaine abusers: association to striatal D2/D3 receptors. Hum Brain Mapp e-pub ahead of print 21 August 2014 doi:10.1002/hbm.22617.

Wise RA, Bozarth MA (1987). A psychomotor stimulant theory of addiction. Psychol Rev 94: 469-492.

Yager LM, Robinson TE (2010). Cue-induced reinstatement of food seeking in rats that differ in their propensity to attribute incentive salience to food cues. Behav Brain Res 214: 30-34.

Yager LM, Robinson TE (2013). A classically conditioned cocaine cue acquires greater control over motivated behavior in rats prone to attribute incentive salience to a food cue. Psychopharmacology (Berl) 226: 217-228.

Supplementary Information accompanies the paper on the Neuropsychopharmacology website (http://www.nature.com/npp) 